Ballala, Celallel, Dalii, Felioque prioris. Cesane, Camesnes, Fesinon $\left\{\begin{array}{l}\text { Banoco } \\ \text { Faksnoko secundae. }\end{array}\right.$

Tertia Darapri, Drisamis, Darisi, Ferapro.

$\left.\begin{array}{l}\text { Bocaro } \\ \text { Doksamrosk }\end{array}\right\}$ Ferisor habet. Quarta insuper addit

Bamatip, Cametes, Dimatis, Fesapto, Fesistot.

If these verses sound ridiculous, it may be remembered that on first acquaintance with the original ones, it needed some awe of the Science of Sciences to induce one to take them seriously. The alliteration perhaps is a little fulsome. But indeed they are not meant for poetry. According to Pope's maxim, "In every work regard the mriter's end," they ought to be criticised as a mnemonic. Looked at in that light the chief drawback from the advantages of the above proposal seems to be, that none of the new names has any meaning, except as a mnemonic; whereas a few of the old names were Latin words : bat it may be disputed whether that was a mnemonic advantage. And at any rate it seems a sufficient offset to say that there will no longer be as much point as formerly in calling these verses 'barbarous'.

Cabthth Rhad.

\title{
CONDITIONAL PROPOBITIONB.
}

The usual treatment of Conditional Propositions has several defects. In the first place it overlooks a most important class. The proposition, "He is not a negro and a white," is as truly conditional as the propositions containing the words "if," "or". It asserts that if it be given that he is a negro, it follows that he is not a white, or, if it be given that he is a white, it follows that he is not a negro. It does not assert that he must be the one or the other-he may possibly be a Red Indian. In other words this proposition asserts that the two contained propusitions, " $\mathrm{He}$ is a negro," " $\mathrm{He}$ is a white," cannot at the same time be true, yet that both may at the same time be false. I admit that this can be reduced to two Hypothetical (Conjunctive) propositions. Capability of being reduced to another form ought not however to exclude special treatment, since Disjunctives can be reduced to Conjunctives, and yet they receive special treatment.

Again the usual treatment of Conditional Propasitions is in difficulties regarding the meaning of the little word "or" in Disjunctives. Some writers maintain that the alternatives are exclusive, while others maintain that they are unexclusive "Or" really has the two meanings and both should be taken into account. The necessity of distinguishing at least two kinds of Disjunctives is seen when we try to frame Digjunctive Syllogisms. Thus the modus ponendo tollens is valid when the alternatives are exclugive, invalid when the alternatives are unexclusive. Thirdly, we seek in vain in the ordinary text-books the reason of the division of Conditionals into Hypothetical (Conjunc- 
tive) and Disjunctive. Moreover, the reason of the rules of these classes of propositions is not given. We are told that Conditionals express some kind of dependence between the contained propositions. Why are there only two kinds of dependence, and what are these two kinds ?

These difficulties are avoided if we look upon Conditional Propositions as Categorical propositions which assert that there exists between the parts of the Conditional one of the relations in the scheme of Opposition, viz., Subaltern, Subcontrary, Contradictory, or Contrary. The so-called Hypothetical proposition asserts Subaltern relation between its parts. Subcontrary relation is asserted by unexclusive Disjunctives, Contradictory relation by what are usually called exclusive Disjunctives, and Contrary relation by propositions like that at the beginning of the article. The proposed division would therefore stand thus :-

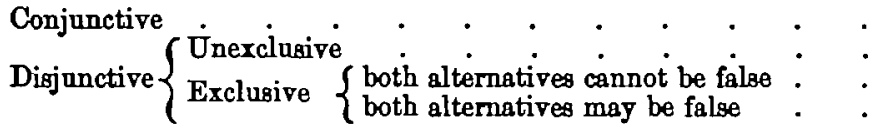

It can easily be that this mode of treatment avoicls the difficulties above mentioned. Thus, the proposition at the beginning of the article comes under class (4). When "or" is taken exclusively, the proposition will belong to class (3), when unexclusively, the proposition will belong to class (2). Lastly, this scheme gives the rationale of the division and rules of Conditionals by showing the connexion between these propositions and the division and rules of Opposition. A fow instances will perhaps make this clear.

"If he is a man, he is an animal." This means the fact of his being a man includes his being an animal. In other words, the eecond proposition is included in the first, which is exactly Subaltern relation. Hence we easily see the reason of the rules of these propositions Affirm the anteredent, or, in other words, the whole, and the consequent, or part, must follow. Deny the consequent, or part, and of course the antecedent or whole is denied.

"He is either black or not black." This asserts that the two contained propositions, $\mathrm{He}$ is black, $\mathrm{He}$ is not black, cannot at the same time be true, yet one of them must be true. This is of course contradictory relation, and the reason of the rules of this class of propositions is at once seen.

I may remark, in conclusion, that the Scholestic text-books give this fourfold division, but, as far as I know, they do not explicitly state the connexion between Conditionals and Opposition.

T. B. Soanneli.

OX THE MOTIVES AND IMPULGES OF THE MIND.

Thr causes, subjectively considered, of all the conscious actions of human beings may be sumned up under three heads :- (1) Motives, (2) Impulses, and (3) Motives and Impulses together. Thus a man will 